\title{
ODABRANA RACIJAAKTIVNOSTI U KONTEKSTU RAČUNOVODSTVENOG TRETMANA ZALIHA NEDOVRŠENE PROIZVODNJE
}

\section{Aleksandra Mitrović ${ }^{1}$, Goranka Knežević}

${ }^{1}$ Univerzitet u Kragujevcu, Fakultet za hotelijerstvo i turizam u Vrnjačkoj Banji, Vrnjačka Banja, Srbija

${ }^{2}$ Univerzitet Singidunum, Beograd, Srbija

\begin{abstract}
Apstrakt:
Specifična pitanja u vezi sa računovodstvenim tretmanom zaliha nedovršene proizvodnje, pored opšte analize finansijskih izveštaja, mogu biti detaljnije razmotrena korišćenjem racio analize finansijskih izveštaja. U tom smislu aktuelnost istraživanja jednog od najkompleksnijih delova imovine, dovela je do potrebe detaljnijeg sagledavanja odabranih racija aktivnosti preduzeća iz oblasti prerađivačke industrije, u kojima su u većoj ili manjoj meri zastupljene zalihe nedovršene proizvodnje. Na taj način omogućena je uporedna analiza grupa preduzeća sa ciljem sveobuhvatnog sagledavanja racija aktivnosti, u kontekstu povezanih specifičnih pitanja u vezi sa računovodstvenim tretmanom zaliha nedovršene proizvodnje, imajući u vidu rizike koje ova vrsta zaliha ima u savremenim uslovima poslovanja.
\end{abstract}

Ključne reči:

racio analiza, racija aktivnosti, zalihe nedovršene proizvodnje.

Razmatrajući zalihe, kao jedan od pojavnih oblika sredstava, neizostavan je detaljniji prikaz zaliha nedovršene proizvodnje (Work-in-process-SAD; Work-in-progressVelika Britanija). Ove zalihe su nužnost $\mathrm{i}$ javljaju se kao posledica proizvodnog procesa i obračunskog perioda, jer su proces proizvodnje i tražnje na samom tržištu retko usklađeni, pa se čak i u okviru jednog proizvodnog procesa javlja neusklađenost različitih delova procesa i vremena završetka. Tehnološki proces proizvodnje utiče na visinu zaliha nedovršene proizvodnje, kao i sama organizacija rada, tako što može uticati na skraćenje vremena proizvodnje, a samim tim i na vreme angažovanja zaliha nedovršene proizvodnje. U vezi sa zalihama nedovršene proizvodnje, razmatranje držanja, nedostatka ili zastarevanja zaliha u savremenim uslovima poslovanja je od velikog značaja, naročito ako se ima u vidu da iznos zaliha nedovršene proizvodnje zavisi od više faktora, među kojima je i specifičnost delatnosti u okviru koje preduzeće posluje i samim tim i rizici koje sa sobom nosi.

Govoreći o zalihama koje su bile predmet mnogobrojnih istraživanja, Rajagopalan i Malhotra (2001, str. 14-24) su proučavali trendove u kretanju materijala, zaliha nedovršene proizvodnje i gotovih proizvoda u periodu od 1961. do 1994. godine u 20 oblasti prerađivačke industrije, sa ciljem utvrđivanja promena u američkom proizvodnom sektoru. Utvrdili su da su materijal i zalihe nedovršene proizvodnje smanjeni u većini oblasti prerađivačke industrije u periodu od 1961. do 1994. godine, dok su zalihe gotovih proizvoda zabeležile pad u nekim sektorima i povećanje u nekoliko drugih, ali nisu pokazale značajan trend promene u više od polovine sektora. Takođe, Chen et al. (2005) su prilikom posmatranja proizvodnih preduzeća u SAD-u, za period od 1981. do 2000. godine, utvrdili da je je došlo do neznatnog smanjenja zaliha, a da je najveće smanjenje prisutno upravo kod zaliha nedovršene proizvodnje. Ako u svrhe analize zaliha u Republici Srbiji uvrstimo prikaz strukture zaliha u proizvodnji, nedovršena proizvodnja prema podacima autora Knežević et al. (2013, str. 90) čini 21\%. Potrebu 
za istraživanjem specifičnosti upravo ovog dela zaliha uvidećemo kroz ulogu i značaj koji ima u preduzećima, preko specifičnih pitanja računovodstvenog tretmana.

Stevanović i Malinić (2009) smatraju da informacioni interesi različitih korisnika finansijskih izveštaja, pored uvida u podatke sadržane u finansijskim izveštajima, mogu biti značajno dopunjeni opštom analizom finansijskih izveštaja, a najviše racio-analizom finansijskih izveštaja. U tom smislu, ovim radom su detaljnije objašnjena racija aktivnosti u kontekstu računovodstvenog tretmana zaliha nedovršene proizvodnje, kroz racio analizu (detaljnije o racio analizi: Mitrović et al., 2015) na osnovu informacija prezentovanih u zvaničnim finansijskim izveštajima preduzeća iz oblasti prerađivačke industrije.

\section{ULOGA I ZNAČAJ RACIJA AKTIVNOSTI U KONTEKSTU RAČUNOVODSTVENOG TRETMANA ZALIHA NEDOVRŠENE PROIZVODNJE}

Analiza racija aktivnosti ima veliki značaj prilikom sagledavanja računovodstvenog tretmana zaliha nedovršene proizvodnje, zbog mnogobrojnih pokazatelja koji mogu ukazati na značaj i ulogu zaliha nedovršene proizvodnje u preduzećima. Koeficijent obrta poslovne imovine, koeficijent obrta obrtne imovine, koeficijent obrta zaliha, koeficijent obrta zaliha nedovršene proizvodnje, u kontekstu računovodstvenog tretmana zaliha nedovršene proizvodnje, mogu dati odgovore na određena pitanja u vezi sa zalihama.

Koeficijent obrta zaliha zavisi od iznosa zaliha iskazanih u bilansu stanja, samim tim i od likvidnosti preduzeća, i predstavlja meru za efikasno upravljanje zalihama. Viši koeficijent obrta znači efikasnije upravljanje zalihama, odnosno kraće vreme zadržavanja zaliha u skladištu, ali to svakako ne znači da visok koeficijent obrta zaliha ne treba pažljivo analizirati. Nizak rezultat koeficijenta obrta zaliha je pokazatelj neefi- kasnog upravljanja i može biti rezultat niskog kvaliteta proizvodnje, vrednovanja zaliha po visokoj ceni, uključivanja bezvrednih i starih proizvoda u zalihe, i drugo. Kako bi koeficijent obrta zaliha imao smislen i uporediv odnos na osnovu koga se mogu donositi odluke, mora se uporediti sa koeficijentom iz prethodnih godina i sa koeficijentom drugih preduzeća iste delatnosti, jer rezultat ovog koeficijenta nije standardizovan, i zavisi od prirode industrije (Mittal, 2010, str. 70).

Kako navodi Bose (2006), idealno, zalihe treba da čine između 12 i $20 \%$ vrednosti prodaje. Kao takav, koeficijent obrta zaliha treba da bude u opsegu od 5 do 8,3 , dok se smatra da isti može biti 9 , pa se preporučuje da koeficijent obrta zaliha treba da bude između 5 i 9. Prema istom autoru koeficijent obrta zaliha u preduzećima u Indiji je samo 1, te se ukazuje na spor obrt zaliha kao dela obrtne imovine. Ako sagledamo koeficijent obrta zaliha pojedinih zemalja u automobilskoj industriji i to: Japana, SAD-a i Indije od 1950. do 1992. godine, može se uočiti kako je iz godine u godinu, počevši od 1950. godine, prisutan trend rasta koeficijenta obrta zaliha u Japanu, SAD-u i Indiji, ali je daleko veći procenat povećanja u Japanu, u odnosu na Indiju i nešto manji u odnosu na SAD (Bose, 2006). Koeficijent obrta zaliha je 1950. godine u Japanu i SAD-u iznosio 3, dok je u Indiji bio 1, a 1992. godine koeficijent obrta zaliha u Japanu iznosio je 45,5, u SAD-u 21, a u Indiji 7,5 (Grafikon 1).

Zalihe nedovršene proizvodnje, kao deo zaliha preduzeća, odnosno imovine, koriste se i za potrebe racio analize. Samim tim, korišćenjem ovih pozicija, veličina zaliha utiče na iznose pojedinih racio pokazatelja i tako utiče na donošenje određenih poslovnih ili finansijskih odluka u preduzeću. Ako sagledamo direktan pokazatelj obrta nedovršene proizvodnje, koji pokazuje odnos cene koštanja gotovih proizvoda predatih skladištu i prosečnih zaliha nedovršene proizvodnje, možemo reći da pokazuje koliko puta se zalihe nedovršene proizvodnje „obrnu” u toku godine. Koeficijent obrta pokazuje kojom se brzinom ostvaruje finalizovanje proizvoda, dok vremensko trajanje pokazuje koliko vremena traje

Grafikon 1. Koeficijent obrta zaliha u automobilskoj industriji Japana, SAD-a i Indije 
dovršavanje proizvoda. Duži ciklus proizvodnje znači i viši obim zaliha nedovršene proizvodnje i obrnuto. Predložena norma trajanja vezivanja zaliha nedovršene proizvodnje je niža od 15 dana, ali je u većini preduzeća taj period mnogo duži, što je rezultat neadekvatnog upravljanja zalihama koje utiču na profitabilnost preduzeća (Bose, 2006, str. 67).

\section{ANALIZA ODABRANIH RACIJA AKTIVNOSTI U KONTEKSTU RAČUNOVODSTVENOG TRETMANA ZALIHA NEDOVRŠENE PROIZVODNJE}

U nastavku je izvršena analiza na osnovu informacija prezentovanih u zvaničnim finansijskim izveštajima preduzeća, iz oblasti prerađivačke industrije. Kao izvor podataka i korišćenih pozicija upotrebljeni su zvanični finansijski izveštaji preduzeća za 2010, 2011, 2012. i 2013. godinu, koji su dostupni na sajtu Agencije za privredne registre, i to prema zastupljenosti zaliha nedovršene proizvodnje i prema veličini posmatranih preduzeća. Tako se uočava da strukturu uzorka čini 24 velikih $(26,09 \%)$ i 68 srednjih $(73,91 \%)$ preduzeća (Grafikon 2). Veličina preduzeća je određena prema podacima koje javno objavljuje Agencija za privredne registre (finansijski izveštaji i podaci o razvrstavanju za 2014. godinu).

Grafikon 2. Struktura preduzeća iz oblasti prerađivačke delatnosti prema veličini preduzeća

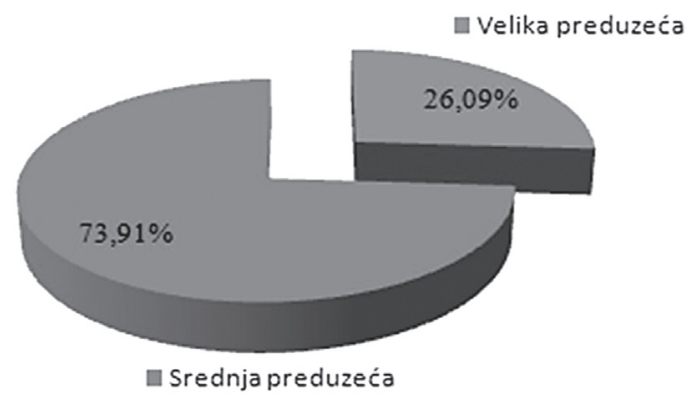

Izvor: Izrada autora
Analiza je izvršena korišćenjem statističkog softvera za obradu podataka SPSS 19.0, na osnovu aritmetičke sredine i podele preduzeća na određene logične grupe prema srodnosti delatnosti, a u okviru prerađivačke industrije. Zbog velikog broja šifri delatnosti koje postoje u okviru prerađivačke industrije, respektujući moguću srodnost određenih oblasti delatnosti, a u skladu sa iznosom i značajem koji postojanje zaliha nedovršene proizvodnje može imati u okviru ovih grupa, izvršena je podela na grupe istraživanja. U okviru grupe 1 analizom je obuhvaćeno 30 velikih i srednjih preduzeća koja posluju u okviru šifara delatnosti: 10 - Proizvodnja prehrambenih proizvoda i 11 - Proizvodnja pića. Takođe, Grupu 2 čini 30 velikih i srednjih preduzeća koja posluju u okviru šifara delatnosti: 22 - Proizvodnja proizvoda od gume i plastike, 23 - Proizvodnja proizvoda od ostalih nemetalnih minerala, 24 - Proizvodnja osnovnih metala i 25 - Proizvodnja metalnih proizvoda, osim mašina i uređaja. $\mathrm{U}$ okviru Grupe 3 analizirana su 32 velika i srednja preduzeća koja posluju u okviru sledećih šifara delatnosti: 27 - Proizvodnja električne opreme, 28 - Proizvodnja nepomenutih mašina i nepomenute opreme, 29 - Proizvodnja motornih vozila, prikolica i poluprikolica i 30 - Proizvodnja ostalih saobraćajnih sredstava. Statistička analiza koja je korišćena u okviru ovog dela, omogućila je poređenja prema grupama istraživanja u okviru prerađivačke industrije, kako bi se utvrdili povoljni i nepovoljni efekti, posmatrano na nivou delatnosti. Uzimajući u obzir da je uzorak slučajan, a da su prilikom analize podataka i korišćenja pozicija finansijskih izveštaja, preduzeća iz oblasti prerađivačke industrije podeljena na tri pomenute grupe, svakako se kao nedostatak ističe broj šifara delatnosti u okviru jedne analizirane grupe i struktura analiziranih grupa. Ovo ograničenje otvara i moguće pravce novih istraživanja i uporednih analiza mnogih šifara delatnosti ili grupa u okviru prerađivačke industrije.

U skladu sa potrebama predmeta rada, korišćeni su sledeći racio pokazatelji aktivnosti: koeficijent obrta ukupne imovine, koeficijent obrta obrtne imovine, koeficijent obrta zaliha i koeficijent obrta zaliha nedovršene proizvodnje. U tabeli 1 su prikazani korišćeni pokazatelji aktivnosti, kao i način njihovog obračuna.

Tabela 1. Način obračuna korišćenih racija aktivnosti

\begin{tabular}{lc}
\hline \multicolumn{1}{c}{ Naziv pokazatelja } & Način obračuna \\
\hline Koeficijent obrta poslovne imovine & Prihodi od prodaje \\
\hline Koeficijent obrta obrtne imovine & Prosečan saldo poslovne imovine \\
\cline { 2 - 2 }
\end{tabular}

Koeficijent obrta zaliha

(Troškovi proizvodnje + Povećanje vrednosti zaliha učinaka - Smanjenje vrednosti zaliha učinaka*)

Prosečan saldo zalliha

Koeficijent obrta zaliha nedovršene proizvodnje

Cena koštanja završenih gotovih proizvoda

Prosečan saldo zaliha nedovršene proizvodnje

Izvor: Izrada autora na osnovu Matan \& Libman (2007, str. 265) 


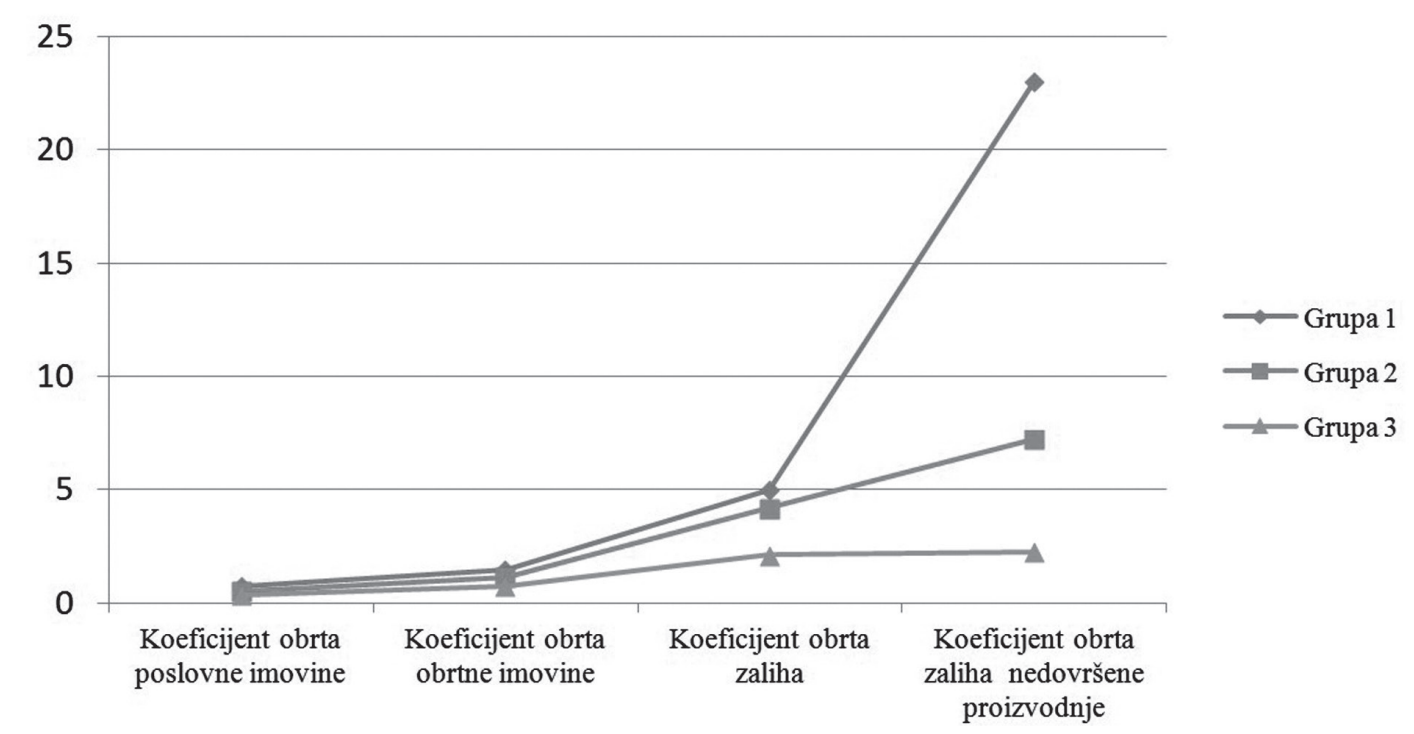

Izvor: Izrada autora

Grafikon 3 prikazuje kretanje koeficijenta obrta poslovne imovine, koeficijenta obrta obrtne imovine, koeficijenta obrta zaliha i koeficijenta obrta zaliha nedovršene proizvodnje prema grupama istraživanja, gde je jasno istaknuta razlika ostvarenih prosečnih pokazatelja prema grupama istraživanja.

Uporednom analizom kretanja prosečnih vrednosti koeficijenta obrta poslovne imovine, koeficijenta obrta obrtne imovine, koeficijenta obrta zaliha i koeficijenta obrta zaliha nedovršene proizvodnje prema grupama istraživanja i godinama, može se uočiti da je najviši iznos svih prethodno prikazanih koeficijenata posmatranih grupa uočen za preduzeća iz Grupe 1 (proizvodnja prehrambenih proizvoda i pića), dok preduzeća iz Grupe 3 (proizvodnja električne opreme, nepomenutih mašina i opreme, motornih vozila, prikolica i poluprikolica i ostalih saobraćajnih sredstava) u istom posmatranom periodu karakterišu najmanji iznosi prethodno nabrojanih koeficijenata.

Prosečne vrednosti kretanja koeficijenta obrta poslovne imovine prema grupama posmatranja, pokazuju da je najviši iznos koeficijenta obrta poslovne imovine karakterističan za Grupu 1 i to 0,76, zatim za Grupu 2 - 0,53 i najniži iznos, za Grupu 3 - 0,37 (Grafikon 3). Prosečne vrednosti kretanja koeficijenta obrta obrtne imovine prema grupama posmatranja, pokazuju da je najviši iznos koeficijenta obrta obrtne imovine ostvarila Grupa 1 i to 1,45, zatim Grupa 2 - 1,14 i najniži iznos, Grupa 3 - 0,75 (Grafikon 3). Koeficijent obrta obrtne imovine pokazuje „najsporiji” obrt za preduzeća Grupe 3, što može biti dejstvo mnogih faktora uticaja obrta na zalihe materijala, zatim nedovršenu proizvodnju i gotove proizvode. Uporednom analizom iznosa koeficijenata obrta zaliha prethodno navedenih grupa delatnosti, može se uočiti da viši iznosi koeficijenata obrta zaliha pokazuju veću efikasnost, samim tim i ostvarenje većih učinaka, i u krajnjoj liniji veće prihode od prodaje koji utiču na povećanje finansijskog rezultata. Pri svemu tome, mora se imati u vidu da specifičnosti proizvodnje (proizvoda), samog tehnološkog procesa, vremena trajanja proizvodnje i drugih faktora, umnogome utiču na iznose zaliha u preduzećima različitih grupa delatnosti korišćenih u istraživanju, i samim tim utiču i na koeficijent obrta zaliha. Ako uporedimo prehrambene proizvode i motorna vozila, na osnovu nekoliko faktora koji utiču na specifičnost proizvodnje, a to su: vrsta proizvoda, tehnološki proces i vreme trajanja proizvodnje, i mnogobrojnih koji počevši od nabavke, preko proizvodnje do prodaje mogu uticati na iznos zaliha, uvidećemo da će se i koeficijent obrta zaliha ovih proizvoda i grupa delatnosti razlikovati. Prosečne vrednosti kretanja koeficijenta obrta zaliha prema grupama posmatranja, pokazuju da je najviši koeficijent obrta zaliha uočen za Grupu 1 i to 4,98, zatim za Grupu 2 - 4,19 i najniži iznos, za Grupu 3 - 2,11 (Grafikon 3). Ako pogledamo prosečne vrednosti kretanja koeficijenta obrta zaliha nedovršene proizvodnje prema grupama posmatranja, uočavamo da je najviši koeficijent obrta zaliha nedovršene proizvodnje uočen za Grupu 1 i to 22,99, zatim za Grupu 2 - 7,23 i najniži iznos za Grupu 3 - 2,26 (Grafikon 3).

\section{ZAKLJUČAK}

S obzirom da racija aktivnosti imaju veliki značaj u kontekstu računovodstvenog tretmana zaliha nedovršene proizvodnje, ovim radom je izvršena racio analiza na osnovu informacija prezentovanih u zvaničnim finansijskim izveštajima preduzeća iz oblasti prerađivačke industrije. Utvrđeno je da su preduzeća koja posluju u okviru Grupe 1 (proizvodnja prehrambenih proizvoda i pića) iskazala najviše prosečne vrednosti koeficijenta obrta poslovne imovine, koeficijenta obrta obrtne imovine, koeficijenta obrta zaliha i koeficijenta obrta zaliha nedovršene proizvodnje prema grupama istraživanja i godinama, dok su preduzeća iz Grupe 3 (proizvodnja 
električne opreme, nepomenutih mašina i opreme, motornih vozila, prikolica i poluprikolica i ostalih saobraćajnih sredstava) ostvarila najmanje iznose prethodno navedenih koeficijenata.

Neophodno je još jednom istaći da kategorija zaliha i samim tim i postojanje zaliha nedovršene proizvodnje zavise od specifičnosti industrije i delatnosti preduzeća. Na primer, tako se vrsta zaliha koja se može naći u uslužnim preduzećima razlikuje od onih u proizvodnim preduzećima (u kojima uglavnom postoje sirovine, nedovršena proizvodnja i gotovi proizvodi), pa se samim tim razlikuje i njihov računovodstveni tretman. Prethodno navedeno je detaljnije potvrđeno sprovedenim analizama u okviru ovog rada, kroz posmatranje razlika između više oblasti preduzeća koja posluju u okviru prerađivačke industrije, što potvrđuje i uticaj na rizike u savremenim uslovima poslovanja preduzeća.

\section{LITERATURA}

Agencija za privredne registre Republike Srbije. (2014). Pretraga pravnih lica i preduzetnika. Preuzeto sa http://pretraga2. apr.gov.rs/ObjedinjenePretrage/Search/Search

Bose, C.D. (2006). Inventory Management. New Delhi: PrenticeHall of India Private Limited.

Chen, H., Frank, M., \& Wu, O. (2005). What Actually Happened to the Inventories of American Companies Between 1981 and 2000?.Management Science, 51(7), 1015-1031. doi:10.1287/mnsc. 1050.0368
Knežević, G., Stanišić, N., \& Mizdraković, V. (2013). Analiza finansijskih izveštaja. Beograd: Univerzitet Singidunum.

Matan, F., \& Libman, A. (2007). Crash course in accounting and financial statement analysis. New Jersey: John Wiley \& Sons, Inc., Hoboken.

Mitrović, A., \& Vučić, V. (2015). Accounting information in to support function business decision making in the company. Hotel and Tourism Management, 3(2), 89-95.

Mitrović, A. (2016). Računovodstveni tretman zaliha nedovršene proizvodnje: Dokotorska disertacija. Beograd: Univerzitet Singidunum.

Mitrović, A., Knežević, S., \& Veličković, M. (2015). Ratio analysis specifics of the family dairies' financial statements. Economics of Agriculture, LXII (4), 1061-1078.

Mittal, R.K. (2010). Management Accounting and Financial Management. FK Publications.

Rajagopalan, S.. \& Malhotra, A. (2001). Have U.S. Manufacturing Inventories Really Decreased? An Empirical Study. Manufacturing and Service Operations Management, 3(1), 14-24. doi:10.1287/msom.3.1.14.9995

Sarngadharan, M., Rajitha, \& Kumar, S. (2011). Financial Analysis for Management Decisions. New Delhi: PHI Learning Private Limited.

Stevanović, N., \& Malinić, D. (2009). Fenomenologija bilansa informaciona moć, rizici i posledice. Ekonomika preduzeća, 57(3-4), 63-89.

\section{THE SELECTED RATIO ACTIVITIES IN THE CONTEXT OF THE ACCOUNTING PROCESSING OF THE SUPPLIES FROM THE PRODUCTION IN PROGRESS}

\footnotetext{
Abstract:

Many specific questions related to the accounting processing of the supplies from the production in progress, in addition to general analysis of financial statements, can be further examined using ratio analysis of financial statements. In this sense, the actuality of the research of one of the most complex parts of the property, has led to the need for detailed consideration of selected ratios of activities of enterprises from the manufacturing industry, in which, the supplies from the production in progress are present to a greater or lesser extent. In this way, a comparative analysis of groups of enterprises was conducted with an aim to form a comprehensive observation of raids activities, in the context of specific issues related to the accounting treatment of production in progress, bearing in mind the risks that this type of supplies has in the modern business environment.
}

\section{Keywords:}

ratio analysis, ratio activities, production in progress. 